\title{
4
}

\section{Technical Advices for Prostate Needle Biopsy Under Transrectal Ultrasound Guidance}

\author{
Makoto Ohori ${ }^{1}$ and Ayako Miyakawa ${ }^{2}$ \\ ${ }^{1}$ Dept. of Urology, Tokyo Medical University \\ ${ }^{2}$ Dept. of Molecular Medicine and Surgery, Unit of Urology, Karolinska Institute \\ IJapan \\ 2Sweden
}

\section{Introduction}

In the early 1990's when systematic biopsy of prostate using transrectal ultrasonography (TRUS) had just begun, there was enthusiasm for identifying abnormalities and obtaining appropriate samples. Since the occurrences of early small prostate cancer are increasing and identifying tumors using TRUS are somewhat subjective, the efficiency of the method in detecting and staging prostate cancer has decreased. (Ohori, et al. 2003) Instead, many physicians discuss about where and how many biopsy cores should be taken in order to improve the detection-rate of cancer. Clinicians have also focused on the pathological features of cancer in biopsy specimens that sometimes provide significant information to stage prostate cancer. (Satake, et al. 2010) Prostate biopsy itself is not technically challenging and residents as well as fellows are regularly in charge of the biopsy - with or without ultrasound technicians. Those with less experience of TRUS guided biopsy are helped by studying technical advices to get appropriate specimens. At Baylor College of Medicine, Memorial Sloan-Kettering Cancer Center, and Tokyo Medical University we have performed more than 5000 cases of TRUS guided prostate biopsy. This large number of TRUS guided prostate biopsies has provided several technical tips to obtain appropriate tissue samples and to avoid complications such as rectal bleeding. In this chapter we will describe practical methods that will improve prostate biopsy.

\section{Direction of needle}

Non-visible prostate cancer on TRUS has been increased because of the advances in PSA screening. (Ohori, et al.2003) However, there are still occurrences of hypoechoic lesions suspicious for cancer. To obtain an appropriate tissue sample from suspicious lesions, it is better to make the needle tip facing the rectum (Figure 1,2). Otherwise, the needle tip slips away from the prostate so that it may result in inappropriate samples and missing lesions. This is particularly true when the biplane ultrasound probe is used which is close to parallel to the rectum.

When a probe with end-fire is used for a biopsy, the location of the biopsy should be close to the side of urethra (Figure 3). If a needle is located like in figure 3 (left), it may cause long distances between the tip of needle and the prostate capsule so that there is adipose tissue between them. It may cause significant bleeding. Similarly, if one prefers to do biopsy with 
transverse image, the direction of the biopsy device should be as in the figure to reduce the distance between the prostate capsule and tip of the needle (Figure 4).
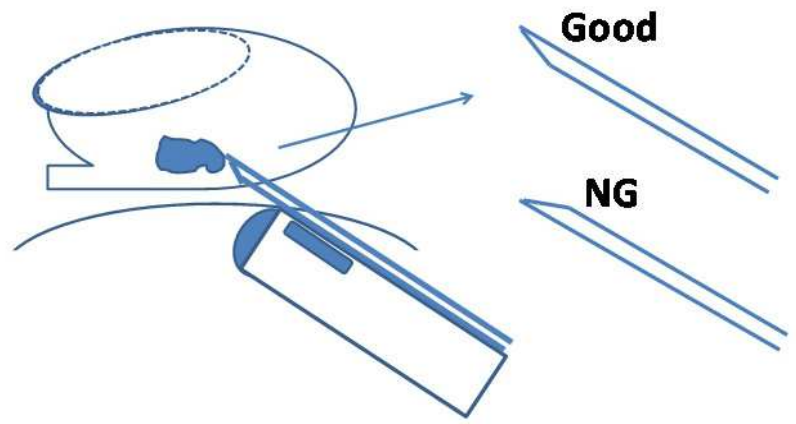

Fig. 1. Tip of needle should face on the side of rectum.

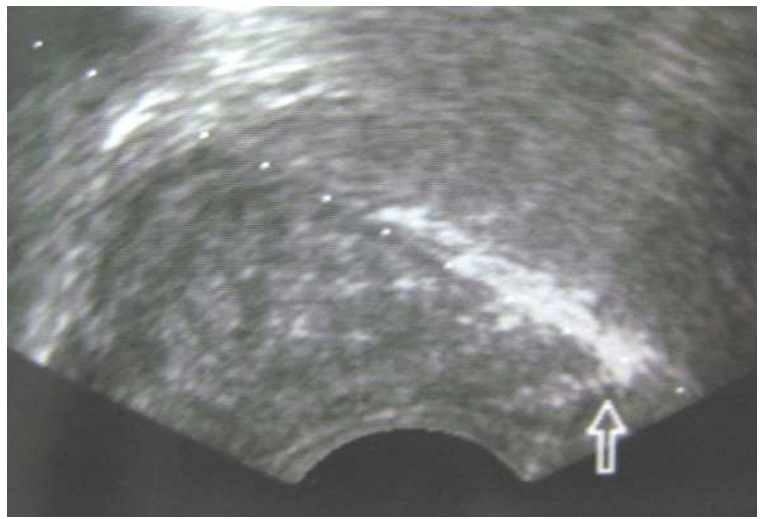

(a)

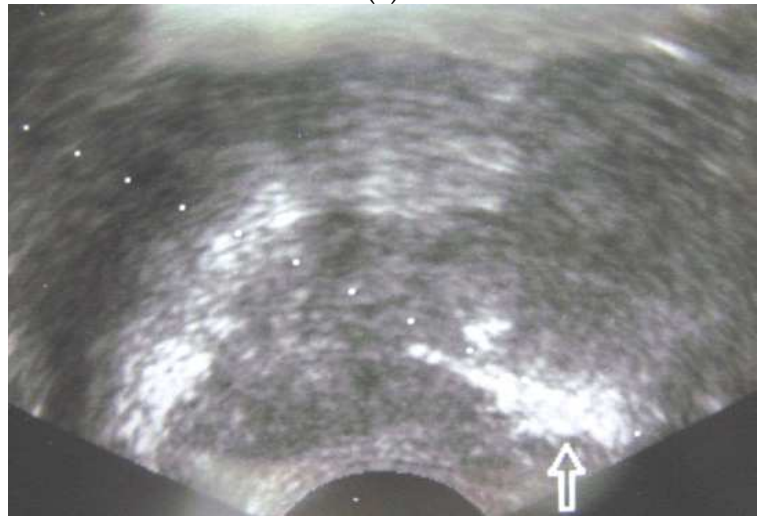

(b)

Fig. 2. A needle goes along the line of needle guide (a). And it slips away from the line when a tip of needle face on the side of prostate (b). 

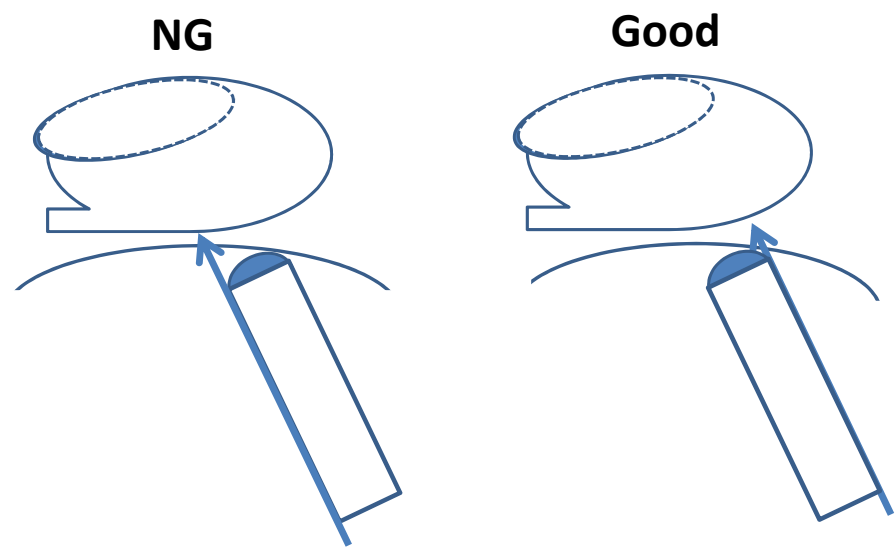

Fig. 3. On sagittal view, biopsy needle should put on the side of apex (Good).
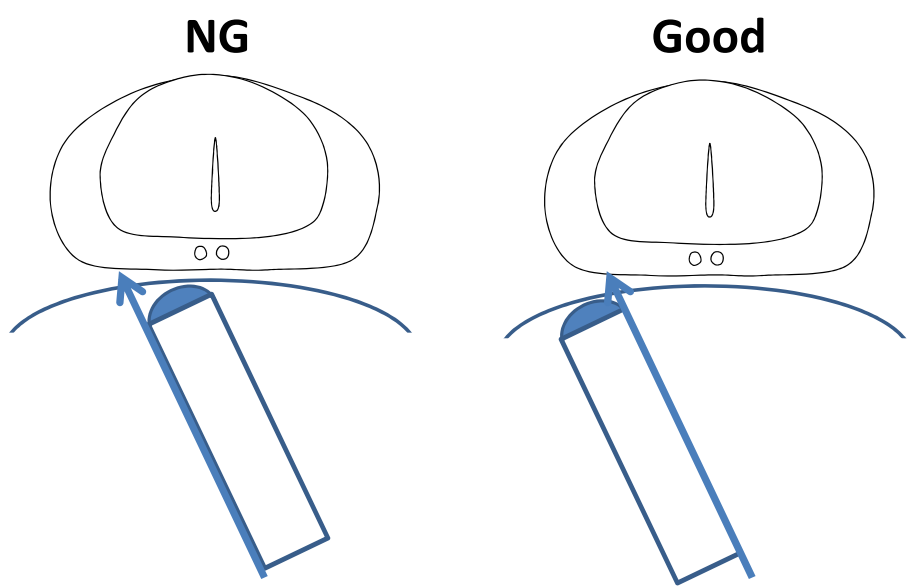

Fig. 4. On transverse view, biopsy needle should put on the right side of ultrasound probe

\section{Where to fire off the needle}

Biopsy itself is a relatively easy procedure. However, pathology reports sometime show the difference between experienced and unexperienced examiners. For instance, the pathology reports occasionally indicate rectal mucosa instead of prostate tissue. It happens because the beginners tend to fire off the needle before it reaches to the prostate capsule. This is the main reason for having excess rectal bleeding after biopsy. When the needle reaches to the prostate capsule, small vessels in the rectal mucosa are pushed away from the needle. The tip of the needle can easily be identified as a high echoic line on TRUS. In addition the examiner could feel the resistance at the prostate capsule (Figure 5). Immediately after the needle reaches to the prostatic capsule, it should be fired off. Even if a needle penetrates the prostatic capsule, it usually does not miss the lesion adjacent to the capsule, since the tip of the needle does not contain a cavity to collect tissue. One may 
try to aim at the prostatic capsule with the biopsy device to assess microscopic extraprostatic disease (Lee F, et al. 1993) but it is actually difficult to diagnose it unless extensive capsular invasion exists at the exact site of biopsy.

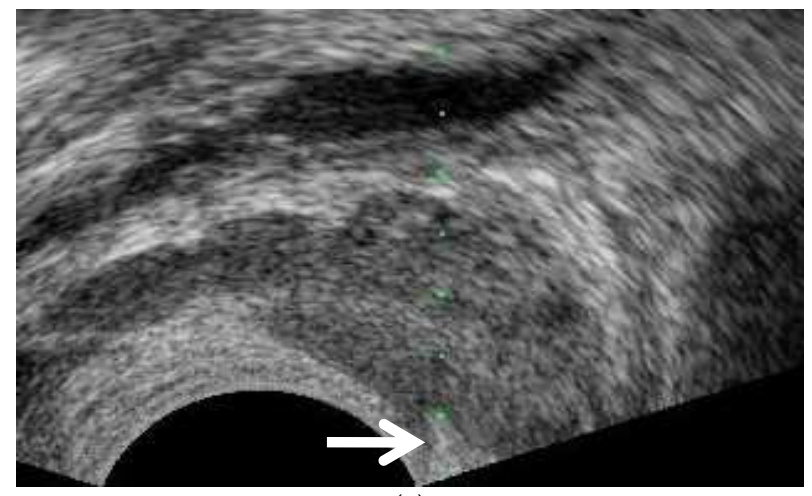

(a)

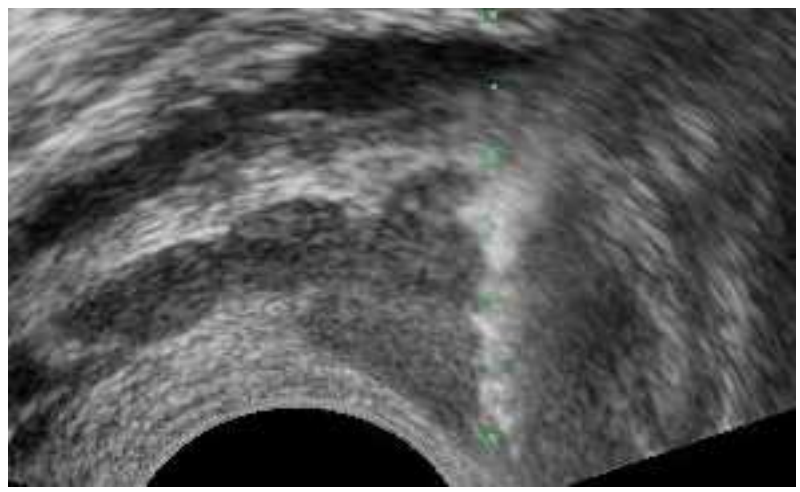

(b)

Fig. 5. A tip of needle is identified as hyperechoic line (arrow). After a tip of needle is identified at the prostatic capsule, then, it should be fired.

\section{Biopsy for transition zone (TZ)}

While significance of TZ biopsy is still controversial, many physicians tend to perform TZ biopsy in a setting of repeat biopsy after initial negative biopsy. Also, several investigators suggested that early prostate cancers are often located in the anterior regions at the level of apex (Figure 6). (Ishii J, et al. 2007, Takashima R, et al. 2002) Some physicians think that with using transperineal biopsy it is easy to get the appropriate samples from the TZ of the prostate. It may or may not be true. We observed many physicians performing transrectal biopsy for TZ. First, many do not insert the needle to the edge of TZ. We should insert the needle deep enough to pass the boundary between the peripheral zone and TZ, though it depends on the size of prostate gland. Because of 
dullness of the tip of the needle and impact of spring loaded automated biopsy gun, it looks like that a needle reaches to the inside of the $\mathrm{TZ}$ area. But commonly it does not reach to inside of the TZ area. The boundary between $\mathrm{TZ}$ and $\mathrm{PZ}$ can be identified by the shape of $\mathrm{TZ}$, calcification and the differences of echogenecity between $\mathrm{TZ}$ and $\mathrm{PZ}$, the locations of ejaculatory duct cysts. Because early prostate cancers tend to locate in the anterior at the level of apex, we should target more distal in the TZ as shown in Figure 7.

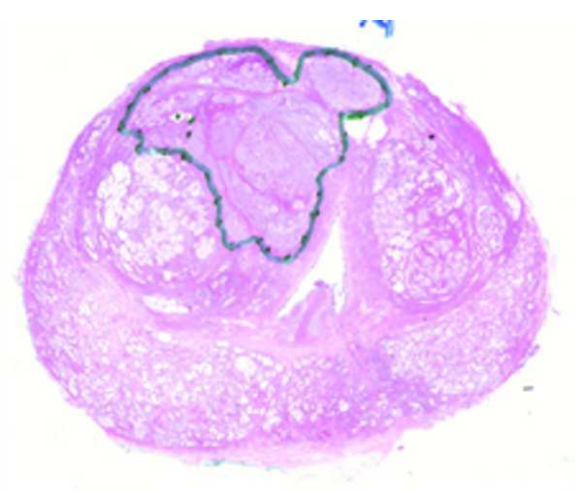

Fig. 6. Whole-mount step section of radical prostatectomy specimen shows large prostate cancer in right transition zone.

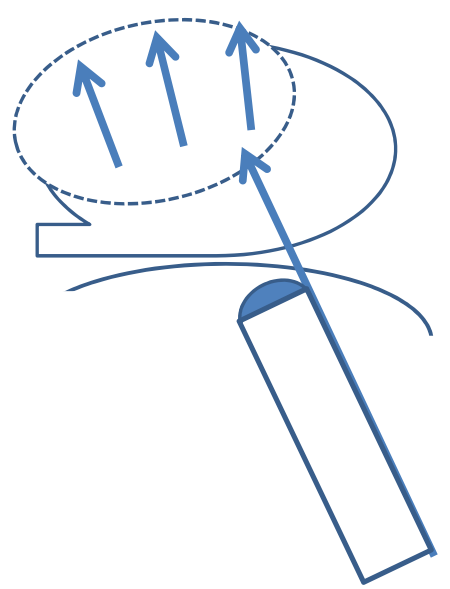

Fig. 7. A needle should be fired after it passes the boundary between TZ and PZ

\section{Biopsy for far lateral prostate}

Since many prostate cancers are located in the far lateral peripheral zone, it is natural to improve the detection rates of cancer when targeting this region. Therefore, for beginners 
it is important to identify where the "far lateral" part of the prostate is located. It is relatively easy to distinguish $\mathrm{PZ}$ from $\mathrm{TZ}$ on transverse views so that simultaneous images of both transverse and sagittal images make far lateral biopsy easy. For the sagittal images only, after identifying the center of prostate such as the line of urethra, then, slowly rotate ultrasound probe to the lateral part, so that far lateral PZ would be identified just after disappearing from TZ. For patients with middle to large prostate, far lateral PZ on sagittal images may sometimes represent only the mid-base of the prostate. To obtain biopsies from the far-lateral part of PZ at the apex, we need to slightly rotate to the center of the prostate .

\section{Biopsy for apical-apex regions}

It is relatively easy to target the region of apex using the end-fire probe. However, when using the biplane probe it can sometimes be difficult because of its angle and structure of biopsy guide. Therefore, it is necessary to puncture the rectal mucosa from the distal part of the apex (Figure 8).

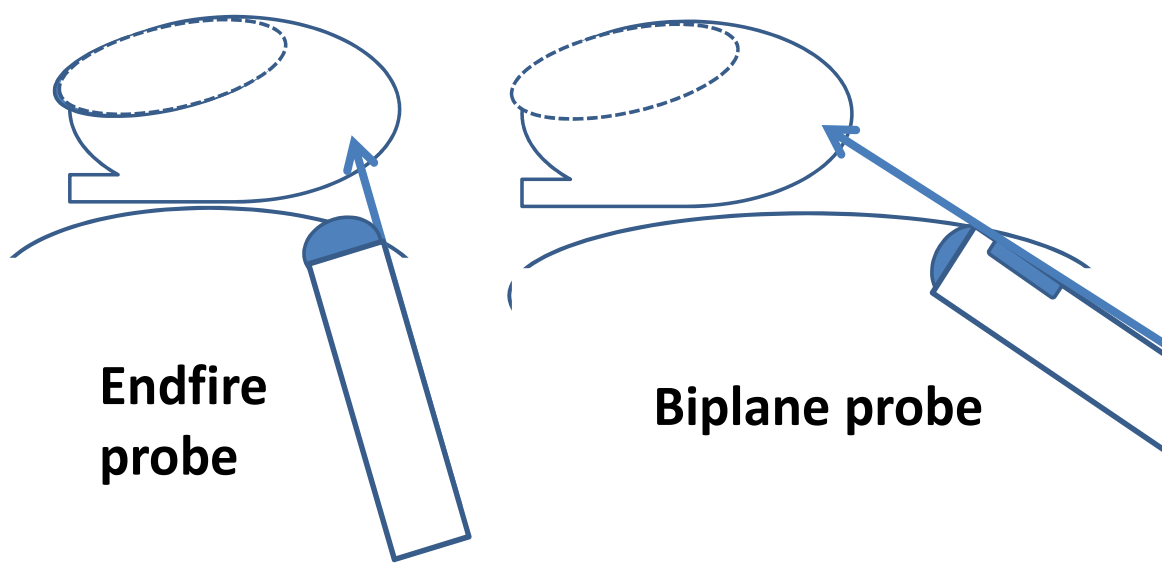

Fig. 8. It is not difficult to target the apex region with end-fire probe. With biplane probe, it may be necessary to puncture rectal mucosa distal from apex to get samples from apex.

\section{Miscellaneous}

Because of the length of the needle and size of device, the examiners sometime bend the needle before firing off the needle (Figure 9). This may harbor the movement of the needle, which may result in inappropriate specimens. Therefore, the examiners should avoid bending the needle and make sure to set it parallel to the biopsy device.

We sometimes observe that there are some cystic lesions in the peripheral zone which indicate the atrophic glands (Figure 10). When this region is biopsied, it is natural to get very scattered specimens. 


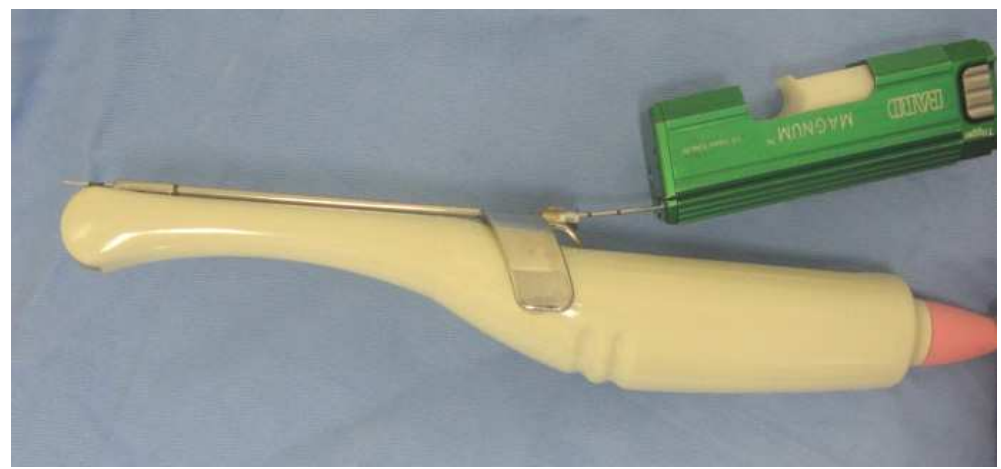

(a)

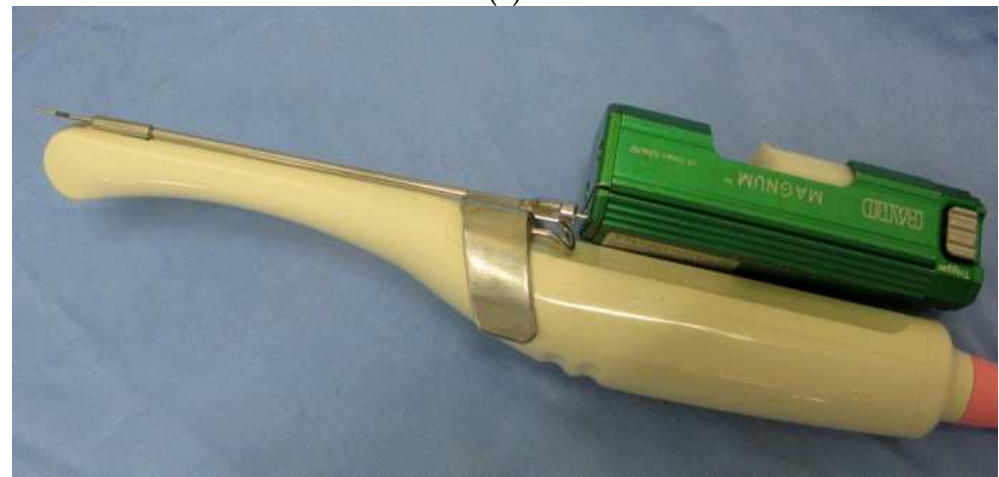

(b)

Fig. 9. When the examiners see the images during biopsy, they tend to bend a needle (a). This may result in inappropriate samples so that a needle should put parallel to the automated biopsy device(b).

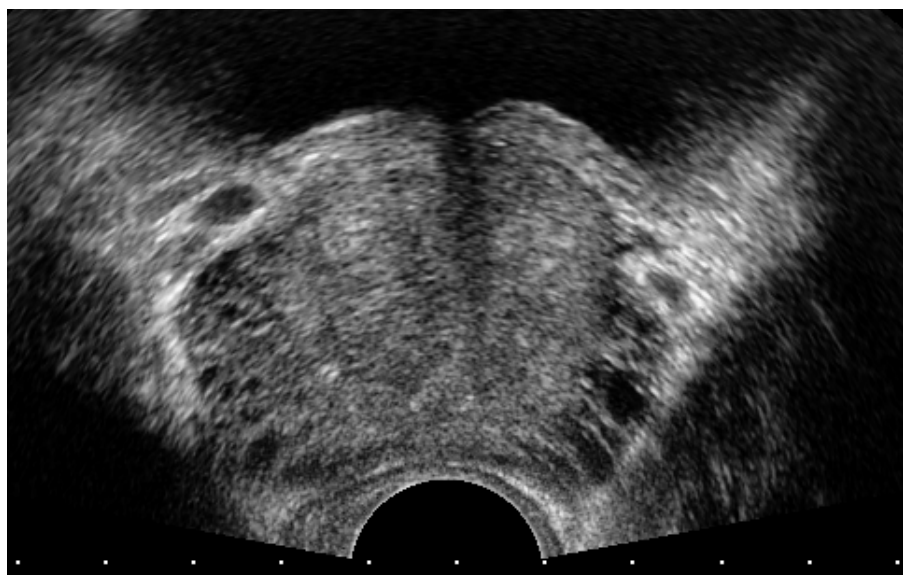

Fig. 10. Atrophic prostate glands in the peripheral zone on TRUS images. 


\section{References}

Ishii J, et al. (2007). Significance of the craniocaudal distribution of cancer in radical prostatectomy (RP) specimens. Int J Urol, Vol 14, 9, pp.817-821.

Lee F, et al. (1993). The role of transrectal ultrasound-guided staging biopsy and androgen ablation therapy prior to radical prostatectomy. Clin Invest Med, Vol. 16, 6, pp. 458470 .

Ohori M, et al. (2003). Do impalpable (T1c) cancers visible on ultrasound differ from those not visible? J.Urol, Vol. 169, 3, pp.964-968.

Satake N, et al.(2010). Development and internal validation of a nomogram predicting extracapsular extension in radical prostatectomy specimens. Int J Urol, Vol.7, 3,pp.267-272.

Takashima R, et al. (2002). Anterior distribution of Stage T1c nonpalpable tumors in radical prostatectomy specimens. Urology, Vol. 59, 5, pp.692-697. 


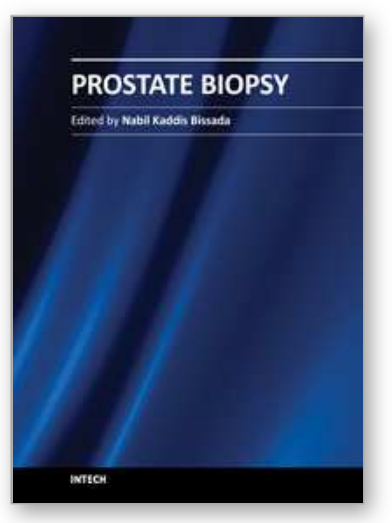

\author{
Prostate Biopsy \\ Edited by Dr. Nabil K. Bissada
}

ISBN 978-953-307-702-4

Hard cover, 134 pages

Publisher InTech

Published online 02, December, 2011

Published in print edition December, 2011

Prostate Biopsy represents the standard procedure for diagnosing Prostate Cancer. This procedure can be performed transrectally, through perineum or occasionally through the urethra. Although the procedures of Prostate Biopsy are covered in numerous publications, there is still a need for gathering different aspects and methods in one source. Hopefully, this book will help physicians in their effort to provide the best treatment for their patients.

\title{
How to reference
}

In order to correctly reference this scholarly work, feel free to copy and paste the following:

Makoto Ohori and Ayako Miyakawa (2011). Technical Advices for Prostate Needle Biopsy Under Transrectal Ultrasound Guidance, Prostate Biopsy, Dr. Nabil K. Bissada (Ed.), ISBN: 978-953-307-702-4, InTech, Available from: http://www.intechopen.com/books/prostate-biopsy/technical-advices-for-prostate-needle-biopsy-undertransrectal-ultrasound-guidance

\section{INTECH}

open science | open minds

\section{InTech Europe}

University Campus STeP Ri

Slavka Krautzeka 83/A

51000 Rijeka, Croatia

Phone: +385 (51) 770447

Fax: +385 (51) 686166

www.intechopen.com

\section{InTech China}

Unit 405, Office Block, Hotel Equatorial Shanghai

No.65, Yan An Road (West), Shanghai, 200040, China

中国上海市延安西路65号上海国际贵都大饭店办公楼405单元

Phone: +86-21-62489820

Fax: +86-21-62489821 
(C) 2011 The Author(s). Licensee IntechOpen. This is an open access article distributed under the terms of the Creative Commons Attribution 3.0 License, which permits unrestricted use, distribution, and reproduction in any medium, provided the original work is properly cited. 